\title{
SEDIMENTARY CHARACTERISTICS AND DEPOSITIONAL EVOLUTION OF LITTORAL-TIDAL FLAT SYSTEM OF SILURIAN ROCKS IN THE TABEI AREA, TARIM BASIN, NW CHINA
}

\author{
WANG, Y. N. ${ }^{1}-$ XU, H. B. $.^{2 *}-$ ZHANG, S. F. ${ }^{1}-$ XIA, Y. T. ${ }^{3}-$ ZHANG, C. $^{1}-$ SHANG, $.^{1}-$ BAO, C. ${ }^{1}$ \\ ${ }^{1}$ College of Geosciences, Yangtze University, Wuhan, Hubei 430100, China \\ ${ }^{2}$ Key Laboratory of Submarine Geoscience, Second Institute of Oceanography, SOA, Hangzhou, \\ Zhejiang 310012, China \\ ${ }^{3}$ Sinopec Northwest Company, Urumqi 830013, China \\ *Corresponding author \\ e-mail:wyn-ml@foxmail.com
}

(Received $9^{\text {th }}$ Apr 2019; accepted $19^{\text {th }}$ Jun 2019)

\begin{abstract}
The marine clastic rock of the Silurian in the Tabei Area is a favorable reservoir. Based on an analysis of geological data such as core, logging, and seismic information, this study investigated the characteristics and differences of the Silurian rocks in the Tabei area main sedimentary system types. Both tidal flat and littoral have been meticulously depicted. In addition, the paleogeographic environment and depositional evolution features of the Silurian rocks in this area have been remodeled. The obtained results show that: (1) according to the difference in sedimentary environment, tidal flat facies have been subdivided into shallow tidal flat and bay tidal flat. (2) During the Early Silurian stage, the center-western region of the study area developed an incised channel with curved characteristics, which was associated with the coastal plain. (3) The whole Silurian deposition was significantly controlled by tectonic movement. Consequently, under the background of Late Caledonian orogeny, the Tabei area was gradually uplifted, and its depocenter constantly migrated southward. This resulted in the vertical transformation of sedimentary types from an incised channel-coastal plain-shallow tidal flat system to a littoral-bay tidal flat system. Moreover, Backshore and supratidal zone were generally denuded due to uplifting at a later stage.
\end{abstract}

Keywords: sedimentary facies, marine clastic rock, Kepingtage formation, stratigraphy, coastal plain

\section{Introduction}

The Tabei Area is located in the northern parts of the Tarim Basin and includes the Halahatang Sag, the Akekule Uplift, the Caohu Sag, and the Shaya Uplift. Vertically, Silurian strata are divided into three formations, namely the Kalpintake formation $\left(S_{1} k\right)$, the Tataiertage formation $\left(S_{1} t\right)$, and the Yimugantawu $\left(S_{2} y\right)$ formation from low to upper levels. In particular, the Yimugantawu formation was missing because it was denuded during the early Hercynian movement. Moreover, Kalpintake formation was subdivided into three parts, which are the lower part of the Kalpintake formation $\left(\mathrm{S}_{1} \mathrm{k}^{1}\right)$, the middle part $\left(\mathrm{S}_{1} \mathrm{k}^{2}\right)$, and the upper part $\left(\mathrm{S}_{1} \mathrm{k}^{3}\right)($ Fig. $l a, b)$.

During the Late Caledonian movement, sedimentary the facies of the Silurian in the Tabei area was controlled by factors such as constant uplifting and multiple cycles of increasing and descending sea level $(F i g .1 c, d)$. With constant discoveries of oil and gas reservoirs, marine clastic rocks as favorable reservoirs developed in the Silurian formations, have attracted the attention of experts and scholars. 


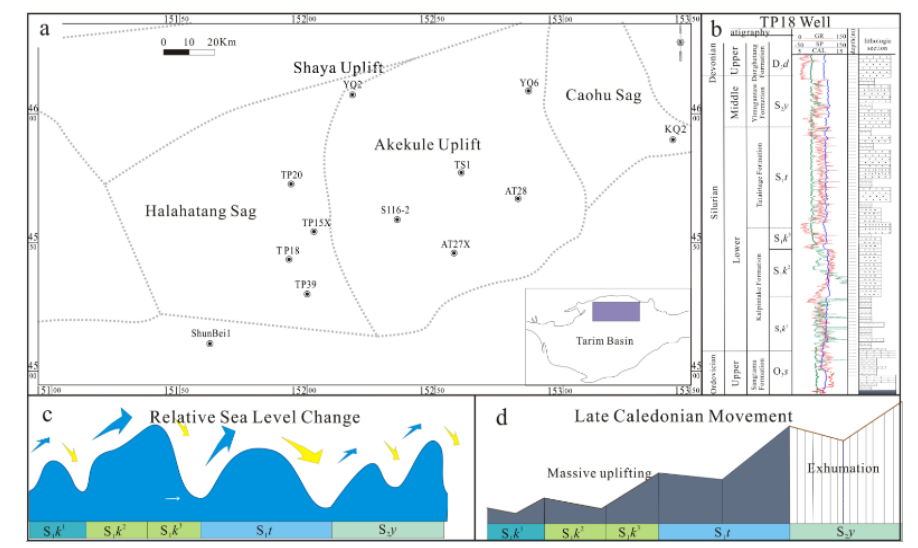

Figure 1. Tectonic setting and stratigraphic characteristics in the Tabei area

In recent years, the study of sedimentary facies of marine clastic rocks has achieved significant progress both in China and internationally. For example, Yamashita et al. (2009) analyzed the coefficient of variance (CV) of grain-size distribution and reported the threedimensional distribution of the tidal flat sand body in the estuary of the Chlamara River. Tillmann and Wunderlich (2014) combined the ground penetrating radar (GPR) with sedimentology and defined different coastal environments of southern Sylt, an island in the North Sea. Zhao et al. (2015) proposed the use of grain-size-sensitive indicators to identify sedimentary facies in a study of modern tidal flat sediments. Gong et al. (2018) studied the relationship between the evolution of tidal channels and the changing sea level. In combination, these studies offer a new way of thinking for the study of marine clastic rocks. Furthermore, many studies have investigated the sedimentary characteristics and the depositional systems of the Silurian in the Tarim Basin. For example, Hu et al. (2007), Jiang et al. (2009), Liu et al. (2016), and Zeng et al. (2018) all suggested that the Tarim Basin developed a barrier-free clastic littoral, offshore shelf, tidal flat, and river delta during the Silurian. Niu et al. (2013) studied the sediment source. Liu et al. (2016) studied the palaeogeomorphology evolution during the Silurian in the Tarim Basin. On the one hand, it is important to clarify sedimentary characteristics, the underlying system, and its evolution, as these still remain poorly understood, which restricts the exploration and research of oil and gas resources resources. On the other hand, previous research typically focused on the description of sedimentary facies and their characteristics (El-Wahed, 2010; Guilbaud et al., 2012; Zhang et al., 2012; Zhang, 2014; Zhang, 2017). However, they ignored the relationship between the transformations of different sedimentary facies and the influence of tectonic movement. At present, the main questions are as follows: (1) What are the differences between the sedimentary characteristics of both shallow tidal flat and bay tidal flat under different depositional environments? (2) What are the sedimentary characteristics and distributions of the coastal plain and its incised channel? (3) How can different facies transform from one form to the other? The results of this study provide answers for these questions which offer a solid geological basis for further oil and gas exploration and their development.

\section{Materials and methods}

The utilized geological data contains 137 core sample photos of Silurian rocks, logging data, and seismic profiles, which were provided by the Sinopec Group Northwest Petroleum 
Branch. The analysis is based on core observations, identification of sedimentary facies markers, analysis of single well, and interpretation of logging and seismic information. The aim was to define the different types of sedimentary facies and both its subfacies and microfacies. Through seismic profiles information, the sedimentary distribution was determined. Then, the distributions were combined with the tectonic evolution process to identify the depositional filling process and sedimentary systems in each period of the Silurian age.

\section{Results}

\section{Sedimentary types and characteristics}

In the study area, Silurian formations mainly deposited marine clastic rocks, developed tidal flat facies, littoral facies, coastal plain facies, and neritic shelf facies.

\section{Tidal flat facies}

Silurian formations in the Tabei area ware distributed as a clastic tidal flat. During the Early-middle Silurian period, the lower part of the Kalpintage $\left(\mathrm{S}_{1} \mathrm{k}^{1}\right)$ extensively developed the shallow water tidal flat facies, while the upper part $\left(S_{1} k^{3}\right)$ locally deposited the Bay tidal flat facies. Their subfacies are intertidal zone and subtidal zone. Furthermore, its microfacies include mud flat, mixed flat, sand flat, tidal channel, and tidal sand bar.

\section{Shallow tidal flat facies}

The shallow tidal flat facies is distributed throughout the lower part of the lower Silurian Kalpintage formation in the Tabei area. During the early Early Silurian period $\left(\mathrm{S}_{1} \mathrm{k}^{1}\right.$ sedimentary period), a small-scale uplift of the terrain under the late Caledonian movement resulted in a stable subsidence. It is worth mentioning that the sedimentary environment at that time in the study was a wide epicontinental sea without barrier. The waves were weakened due to the particular environment with shallow water and gentle slope. As a result, the area widely developed shallow tidal flat facies, which directly contacted the neritic shelf, forming a widely distributed shallow sea shelf contact.

The log curve and seismic profile of the AT27X well provides the natural gamma (GR) curve of the shallow tidal flat in the lower part of the formation and shows the median value and the dentate type (Fig. 2a). The seismic reflection structure consists of two types: low continuity and middle amplitude as well as high continuity and middlehigh amplitude. The shallow tidal flat facies above the Ordovician system shows the retrogradation progress and reflects the rise of the sea level (Fig. 2b).

\section{Bay tidal flat}

In contrast, bay tidal flat facies is locally distributed in the upper part of the Kalpintage formation $\left(\mathrm{S}_{1} \mathrm{k}^{3}\right)$ and the Tataiertage formation $\left(\mathrm{S}_{1} \mathrm{t}\right)$ of the lower-middle Silurian in the Tabei area. With the sustained enhancement of late Caledonian movement during the Early-Middle Silurian period, except the eastern and western region, the study area was subjected to rapid uplifting and formed a steep slope. At the same time, waves were significantly strengthened. However, the eastern and western 
areas featured by no obvious barrier bay, which could have obstructed wave formation and thus boosted tidal shifts. The facies contacted the shelf or upper nearshore.

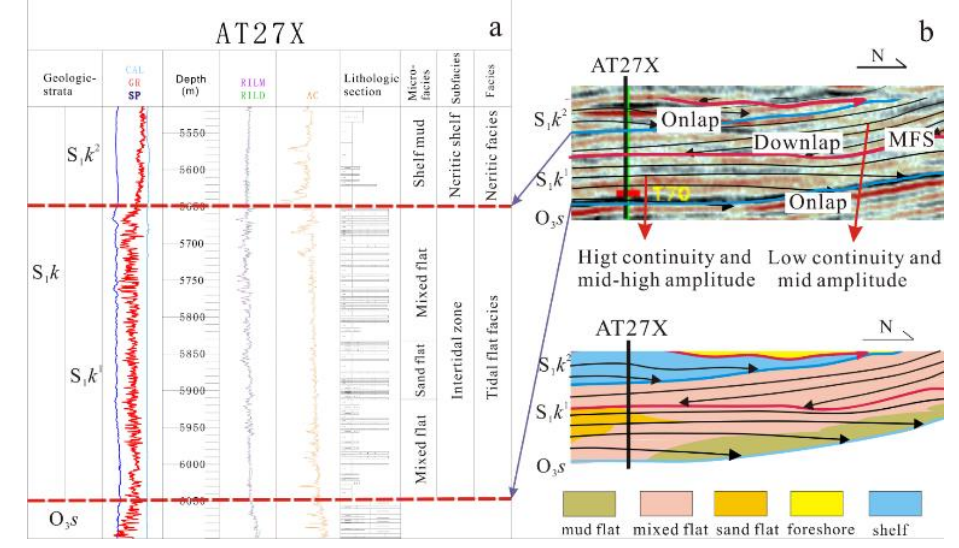

Figure 2. Geophysical response characteristics of shallow tidal flat in the AT27X well

Furthermore, the shallow tidal flat has a relatively high shale content. Its mud flat is well developed and other microfacies contain mixed flat, sand flat, and tidal bar. Especially the tidal channel is little developed. The mud flat consists of grey-green grey mudstone and silty mudstone (Fig. 3a). The mixed flat has an unequal thickness, is interbeded with fine sandstone and mudstone, and developed both tidal bedding and cross bedding (Fig. 3b, c, d). The lithology of the sand flat consist of gray-green gray fine litharenite with separation, cross bedding, and oblique bedding (Fig. 3e).

Because the strong uplift led to a rapid decrease of relative sea level, rocks of the bay tidal flat facies contain less muddy sediment but more sandy depositions, which differs from shallow tidal flat. It includes grey-green grey brown sandstone, reflecting the weak reduction/weak oxidation sedimentary environment. Its tidal channels are well developed and other microfacies include mixed flat, sand flat, and tidal sand bar, but no mud flat.

Then, the characteristics of the tidal channel lithology contains comparatively rough granularity with poor separation. Furthermore, the fine-coarse litharenite is visible. Sandy, argillaceous, and lime conglomerate developed at the bottom, with many erosion and truncated surfaces, and the fine gravelly deposit (Fig. 3f, g, $h$ ).

\section{Littoral facies}

Under the background of late Caledonian movement during the Early-Middle Silurian period, the central part of the Tabei area was greatly uplifted and became steep. Consequently, the hydrodynamic wave force was greatly strengthened. As a result, the upper part of the Kalpintage formation $\left(S_{1} k^{3}\right)$ and the Tataaiertage formation $\left(S_{1} t\right)$ developed littoral deposition.

In general, the facies have three main features in common: (1) as the near source deposits, the have a general composition and structural maturity; (2) the foreshore and nearshore developed, while backshore lacked. According to the lithologic difference of nearshore, the latter can be subdivided into an upper shoreface and a lower shoreface; (3) sand bodies were characteristic by acceleration progradation and reverse cycle due to the rapid descending of the relative sea level. 
The lithology of foreshore contains gray and green-grayish medium-fine grained lithic quartz sandstone, with bidirectional cross bedding, oblique bedding, parallel bedding, and bottom scour upgrowing (Fig. $3 i, j, k$ ).

Due to the strong hydrodynamic force at the upper shore face, the lithology contains grey-grey green fine sandstone and gritstone. Parallel bedding and plate cross bedding developed (Fig. 3l, m, n). However, the lower part shore face, with its lower water hydrodynamic condition, is mainly composed of grey fine sandstone and siltstone with few gray-green gray silt and silty mudstone. The sandstone shows parallel bedding and striped argillaceous (Fig. 3o, p).
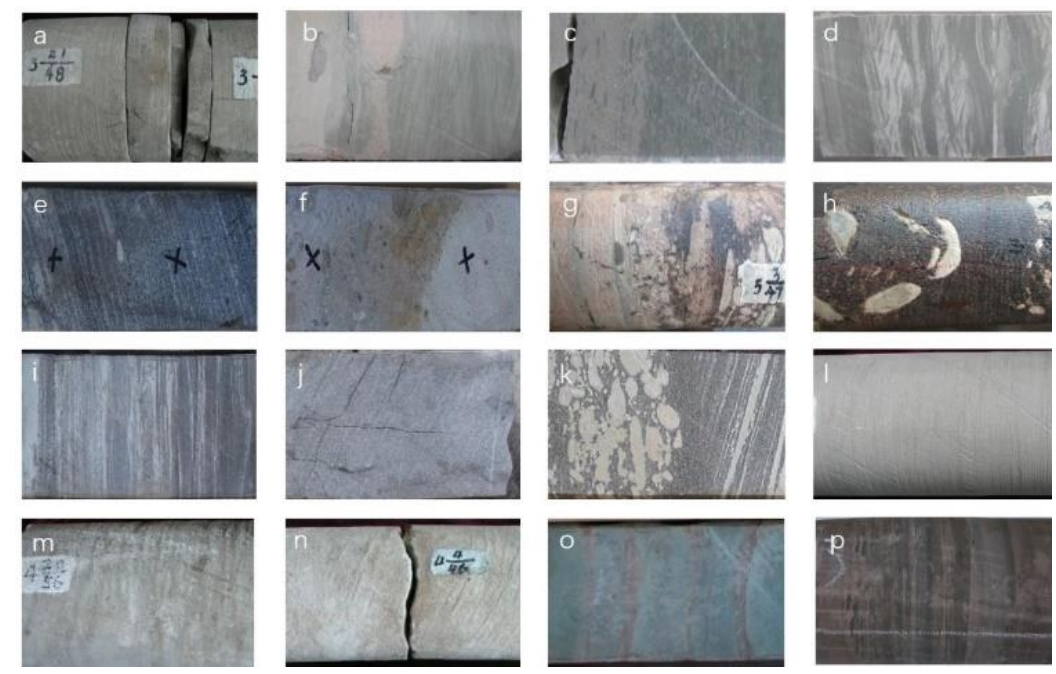

Figure 3. Core of Littoral and tidal flat of the Silurian in the Tabei area. a. grey green horizontal bedding silty mudstone, S119 Well, $5331.5 \mathrm{~m}, S_{\mathrm{l}} \mathrm{k} ; \mathrm{b}$. wavy bedding, mixed flat deposition, S116-2 Well, $5416.4 \mathrm{~m}, S_{1} k^{l}$; c. light-grey green siltstone and grey green mudstone. S110 Well, $5495.06 \mathrm{~m}, \mathrm{~S}_{1} \mathrm{k}^{1}$; d. lenticular bedding, mixed flat deposition. S110 Well, $5487.74 \mathrm{~m}$, $S_{I} k^{l}$; e. oblique bedding and sand flat deposition. TP5 Well, 5508.20-5508.77 m, $S_{1} k^{3} ; f$. greygreen fine sandstone, tidal channel. TP3 Well, $5470.30 \mathrm{~m}, S_{l} k^{3} ;$ g. grey brown fine conglomerate, lime and muddy gravel, tidal channel, TP3 Well, $5470.30 \mathrm{~m}, S_{1} k^{3} ; h$. parallel bedding. TP6 Well, 5711.32-5712.82 m, $S_{1} k^{3}$; i. oblique bedding. TP6 Well, 5711.32-5712.82 m, $S_{1} k^{3} ; j$. bottom erosion. TP11 Well, $5855.35 \mathrm{~m}, S_{1} k^{3} ; k$. grey-green fine sandstone, small cross bedding. S112-2 Well, $5458.4 \mathrm{~m}, S_{1} k$; l. top slaty bedding, $S 119$ Well, $5346.7 \mathrm{~m}, S_{1} \mathrm{k} ; \mathrm{m}$. wave mark. TP2 Well, $5283.01 \mathrm{~m}, S_{1} t ; n$. light-grey green siltstone and fine sandstone with grey green thin-layer silty mudstone TP6 Well, 5708.03-5714.53 m, $S_{1} k^{3}$; o. striped argillaceous. TP22

Well, 6230.84-6231.44 m, $S_{1} k$; p. parallel bedding. TP3 Well, 5471.58-5472.20 m, $S_{l} k^{3}$

\section{Coastal plain}

The coastal plain and its incised channels formed during the early Early Silurian period $\left(\mathrm{S}_{1} \mathrm{k}^{1}\right.$ sedimentary period), and were distributed throughout the Tuopu district, central Tabei. Two main channels developed (Fig. 4a) whose lithology consisted of gray black fine grain lithic quartz sandstone and gray black mudstone with part of silty sand and a large number of brachiopoda. It showed characteristics of high value box type, bell type + funnel type, and bell type + box type of the GR curve (Fig. 4b). The seismic event of the channel through process of erosion and filling can be distinguished as incised valley and the seismic response is a strong amplitude and a medium continuous reflection (Fig. 4c). 


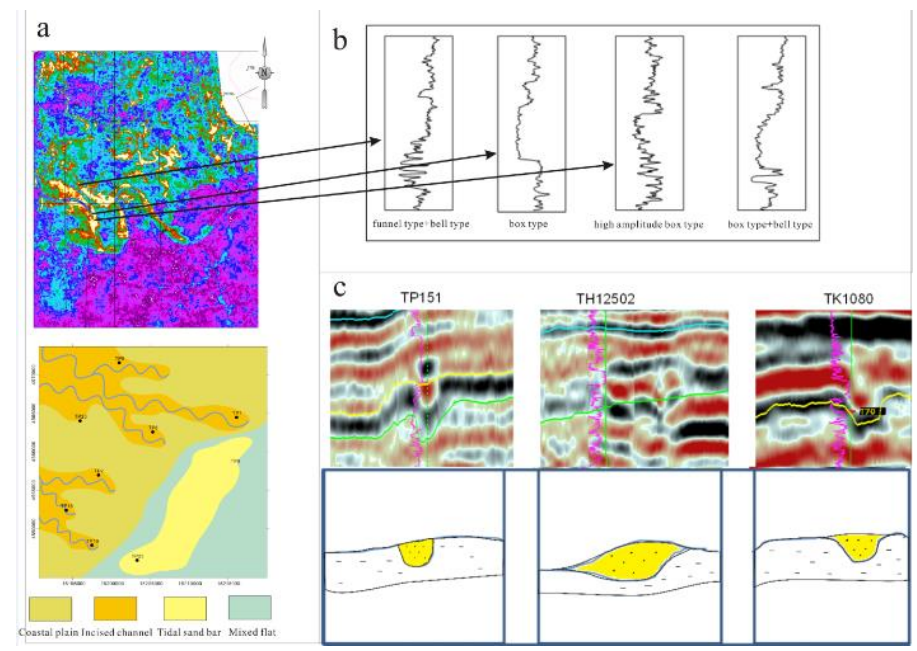

Figure 4. Geophysical response and distribution of coastal plain and its incised channels of the early Silurian period

\section{Discussion}

\section{Depositional filling process}

During the early Early Silurian period $\left(\mathrm{S}_{1} \mathrm{k}^{1}\right.$ sedimentary period), the sedimentary center was located in the northeast of the study area. The uplift was not obvious, which led to a wide sedimentary range with great thickness. The shallow water tidal flat developed (Fig. 5a).

During the period of the middle part $\left(\mathrm{S}_{1} \mathrm{k}^{2}\right.$ sedimentary period), the sea level rapidly rose, a large-scale transgression occurred, the sedimentary center moved southward, and the neristic shelf facies (Fig. 5b) developed. During the period of the upper part $\left(\mathrm{S}_{1} \mathrm{k}^{3}\right.$ sedimentary period), the tidal flat and littoral developed, including sand flat, sandy foreshore, upper of shore, and the lower member (Fig.5c). The depositional period of the Tataaiertage formation ( $\mathrm{S}_{1} \mathrm{t}$ sedimentary period) is mainly dominated by both tidal flat and littoral deposits (Fig. 5d).

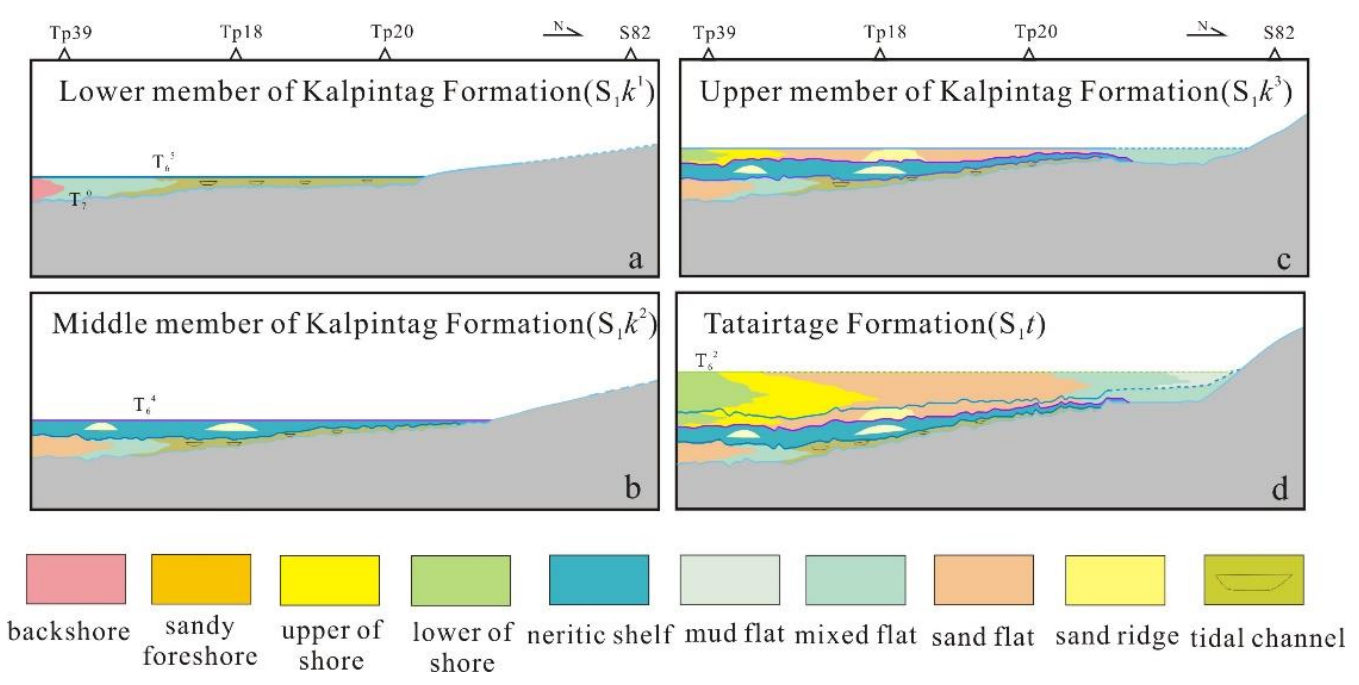

Figure 5. Filling progress of Silurian sedimentary facies in the Tabei area 


\section{Sedimentary system and depositional evolution}

In the lower part of the Kalpintage formation of the Early Silurian age $\left(\mathrm{S}_{1} \mathrm{k}^{1}\right.$ period), the uplift is not significant in the study area. This is a broad epicontinental sea sedimentary environment that features shallow water, gentle slopes, and wide intertidal zones, which results in weak wave action and the wide development of the shallow water clastic rock tidal flat. As a result, it is characterized by the shallow water tidal flat-coastal plain-incised channel depositional system. The tidal flat is stably distributed in east-west direction along the coast, developing sedimentary microfacies of mud flat, mixed flat, and sand flat, which reflects the gradual weakening of tidal hydrodynamic forces from sea and coast. In addition, the mud flat is thin due to erosion caused by the later-stage uplifting. The development of coastal plain deposits in the Tuopu area features two main channels and outwards into tidal flat facies (Fig. 6a).

During the middle part, the tectonic movement resulted in a slight uplift $\left(\mathrm{S}_{1} \mathrm{k}^{2}\right.$ period). At the same time, the sea level rose rapidly, large-scale transgression occurred, and the sediment center migrated southward, which led to the development of the neritic shelf facies in most areas and sand ridges in part of the areas (Fig. 6b).

In the upper part $\left(\mathrm{S}_{1} \mathrm{k}^{3}\right.$ period), the uplifting and topography variation of the Tabei area is more obvious. The center area is raised and the slope increased, which strengthened the wave action. The near source littoral facies developed. However, the relatively gentle slope and the shading of the bay weakened the action of the waves in the west and east area, which is dominated by bay tidal flat facies. Therefore, the Tabei area developed a bay tidal flat-littoral depositional system (Fig. 6c).

During the sedimentary period of the Tataaiertag formation of the Middle Silurian age $\left(S_{1} t\right.$ period), the area inherited the geomorphic features of the upper part and the sedimentary center continued to migrate southward. At the same time, the bay tidal flatlittoral depositional system developed (Fig. 6d).
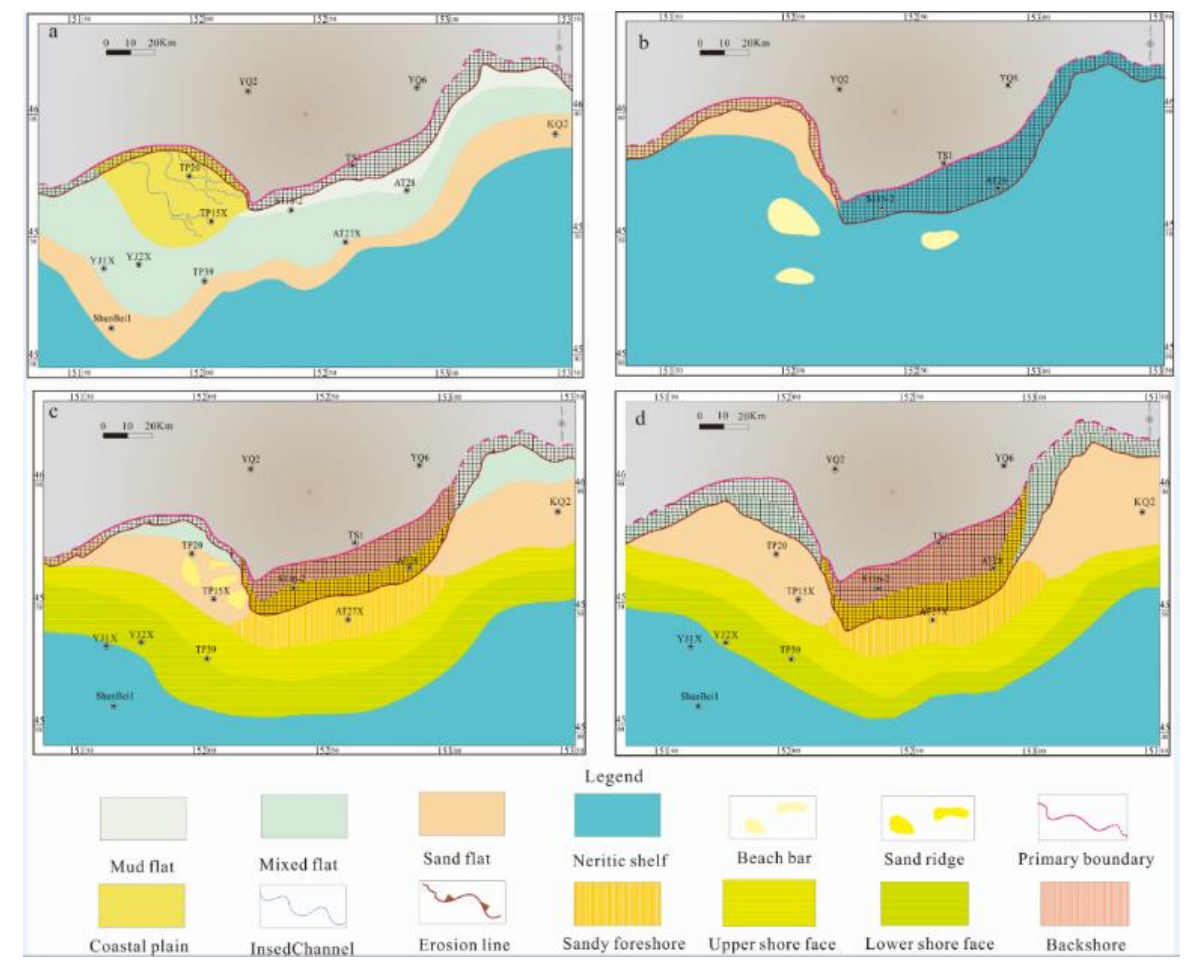

Figure 6. Depositional system and its evolution during the Silurian in the Tabei area 


\section{Conclusion}

(1) The Silurian tidal flat in the study area can be divided into shallow tidal flat and bay tidal flat. The shallow tidal flat is located in the barrier-free and wide epicontinental sea during the stable subsidence period. This is characterized by extensive distribution and high mud content, among which, the mud flat developed very well, but the tidal channel did not develop; distribution in the bay area without obvious barrier during the period of rapidly declining sea level, thus limiting the bay tidal flat. The sand content of rocks is high and the tidal channel developed.

(2) During the Early Silurian period (the $S_{1} k^{1}$ period), the coastal plain and its incised channels in the central-western regions of the study area were characterized by the incised valley shape of the seismic profile, and the high amplitude and medium continuous reflection.

(3) The Silurian deposit is controlled by the late Caledonian movement. The Tabei area continues to rise and the sedimentary center moves southward. The depositional system is transformed from an incised channels-shallow tidal flat system to a littoralbay tidal flat system. Among these, the backshore and the upper tidal zone are generally denuded by the late uplifting.

This research identified the Silurian strata sedimentary characteristics and how they evolved in the Tarim Basin, which provides a basis for further research. In addition, this paper discussed a previously ignored relationship between transformations of different sedimentary facies and the influence of the orogeny of the Late Caledonian. The next step will be to semi-quantitatively determine the relationship between tectonic movement, the changing sea level, and the depositional filling process to establish a relationship model between the depositional filling process and the changing sea level under this specific tectonic setting.

Acknowledgements. We are grateful to the support from Natural Science Foundation of China (project number: 41302095).

\section{REFERENCES}

[1] El-Wahed, M. A. A. (2010). The role of the Najd Fault System in the tectonic evolution of the Hammamat molasse sediments, Eastern Desert, Egypt. - Arabian Journal of Geosciences 3(1): 1-26.

[2] Gong, Z., Yan, J. W., Geng, L., Zhu, S. Y., Li, H., Zhang, C. K. (2018) Mechanisms underlying the dynamic evolution of an open-coast tidal flat-creek system: III: Impact of sea level rise. - Advances in Water Science 29(01): 109-117.

[3] Guilbaud, R., Bernet, M., Huyghe, P., Erens, V., Chirouze, F., Dupont-Nivet, G. (2012). On the influence of diagenesis on the original petrographic composition of MiocenePliocene fluvial sandstone in the Himalayan foreland basin of western-central Nepal. Journal of Asian Earth Sciences 44(1): 107-116.

[4] Hu, S. H., Wang, Q. G., Li, X. Z. (2007). Sequence stratigraphic subdivision and sedimentary system characteristics of Silurian in Tarim Basin. - Journal of Daqing Petroleum Institute 31(2): 8-11 + 122-123.

[5] Jiang, Z., Wang, Y., Wei, C. (2009). Hemipelagic deposition of the Silurian Kepingtage formation in Tarim basin and its sedimentologic significance. - Journal of Earth Science 20(6): 921. 
[6] Liu, H., Somerville, I. D., Lin, C., Zuo, S. (2016). Distribution of Palaeozoic tectonic superimposed unconformities in the Tarim Basin, NW China: significance for the evolution of palaeogeomorphology and sedimentary response. - Geological Journal 51(4): 627-651.

[7] Liu, R. H., Wang, M., Jiang, Z. X. (2016). Development of sedimentary facies type in Silurian lower Kepingtage formation, Tahe Area. - Acta Sedimentologica Sinica 34(2): 326-335.

[8] Niu, L., Yu, B. S., Zhang, W. B. (2013): Provenance analysis and dating of parent rocks of the sandstones from Kepingtage formation (Silurian) in the Northern Tarim Basin. Acta Sedimentologica Sinica 31(03): 421-429.

[9] Tillmann, T., Wunderlich, J. (2014). Barrier spit accretion model of Southern Sylt, German North Sea: insights from ground-penetrating radar surveys and sedimentological data. - Zeitschrift für Geomorphologie (Supplementary Issues) 58(3): 137-161.

[10] Yamashita, S., Nakajo, T., Naruse, H., Sato, T. (2009). The three-dimensional distribution of sedimentary facies and characteristics of sediment grain-size distribution in a sandy tidal flat along the Kushida River estuary, Ise Bay, Central Japan. Sedimentary Geology 215(1-4): 70-82.

[11] Zeng, Q., Zhang, X., Zhang, R., Zhao, J., Hou, G., Ji, Y. (2018). Characteristics of tidal action sedimentary system and distribution of favorable sand bodies of Silurian in Tazhong area, Tarim basin, NW China. - Quaternary International 468: 62-71.

[12] Zhang, J. L., Meng, Q., Qi, J. F. (2012) Characteristics of multi-stage structural deformation and oil and gas accumulation in fault depression basin: a case study of Nember Depression in Hailar-Tamtsag Basin. - Petroleum Geology \& Experiment 34(4): 368-375.

[13] Zhang, T. (2017) Division of tectonic evolution stages in South Beier Sag. - West-China Exploration Engineering 29(50): 110-112 + 115 .

[14] Zhang, Y. (2014) Study on characteristics of prototype basin of Nantun formation in Beier Sag of Hailar Basin. - Petroleum Geology and Engineering 28(6): 12-15.

[15] Zhao, Y. N., Wang, Z. H., Wu, X. X. (2015). Grain size distribution of modern tidal flat sediments at the Yangtze River mouth and its application to identification of sedimentary facies. - Journal of Palaeogeography 17(3): 405-416. 